Brain growth catch-up growth head circumference ecological adaptation mental retardation nutrition

\title{
Growth, Inheritance, and Environment
}

\author{
George G. Graham ${ }^{[21]}$ and Bl.anca Adrianzen T. \\ Grace Department of Research, British-American Hospital, Lima, Peru, and The Johns Hopkins University, Baltimore, Maryland, USA
}

\section{Extract}

Thirteen very poor Peruvian families have been followed for a number of years. Fifteen of their children were admitted to the hospital severely malnourished, with a mean height quotient (height age $\times 100 /$ chronologic age) of 45 , at a mean age of 10.6 months. At 3 years of age, mean height quotient was 60.9 ; at 7 years of age it was 68.9. Forty so-called healthy siblings had height quotients of 62.8 at 1 year, 65.3 at 3 years, and 73.2 at 7 years of age. From 3 to 7 years of age differences were no longer significant. Eighteen siblings were given an optimal diet in a protected environment from shortly after birth until 18-27 months of age. At 18 months of age their mean height quotient was 82.5 . Those who remained in the protected environment had a quotient of 85.09 months later; those who returned home had a mean height quotient of 64.9 1 year later, no longer significantly different from the "malnourished" and "healthy" siblings. There was no difference in head circumference, at the same height, between the recovered malnourished and those whose nutrition was ideal during the first 18-27 months of life. The head circumference, at the same height, was less than the U.S. 50th percentile and more than the 3rd percentile, suggesting a different genetic constitution.

\section{Speculation}

Adverse environmental influences affecting nutrition over the entire growth period are probably as important as inheritance in determining eventual stature of children. Catch-up growth, both in height and in head size, can go on for many years after a period of severe malnutrition. Head size, and presumably brain mass, may not be selectively affected by severe malnutrition in early life and may remain a function of body mass.

\section{Introduction}

Undernutrition of varying degrees affects two-thirds of the world's infants and preschool children. Justifiable concern is expressed over possible permanent sequelae, as well as the excess mortality to which it contributes. Although loss of some of the potential for linear growth and muscle mass present at birth may or may not be a significant consequence, there is no question about the serious handicap to the individual, his family, and society, which a loss of learning potential represents.
Studies of children who had been hospitalized early in life for severe malnutrition have documented subsequent stunting, when compared with well known international standards or with children of like ethnic origin but less disadvantaged situations $[3,6,13]$. These studies admittedly lack information on each child's own genetic potential. In a study [5] an analogous group of children was compared with their own siblings and with a population of very similar socioeconomic status: no deficit in height was apparent. If it is assumed that the "healthy" siblings and the control 
population in this last study represent the true genetic potential, then it might be alleged that a period of severe malnutrition does not result in loss of eventual stature. If, as is more likely, we assume that both groups of "controls" were suffering from chronic undernutrition, then it might be inferred that a finite period of severe malnutrition does not result in a deficit over and above that ensuing from chronic undernutrition. From the initial ages and anthropometric measurements of the children in that study [5], it seems probable that most of them were admitted to the hospital with kwashiorkor, the initial growth lag not being as great as that seen in infants with marasmus in our clinic [6]. This might be an additional reason for the failure to find deficits 7 years later.

In our studies [6], a greater deficit in head circumference than in height was apparent when both were referred to the 50th percentile of the most commonly used standards [14]. Our comparison assumed that Peruvian Mestizo children have head circumferences comparable to those of U.S. children at the same height, and that normal children at the 3rd or 10th percentile in height have head circumferences equal to those of children growing along the 50th percentile at the same height but a younger age. With the publication of more extensive standards for head circumference [11], this now seems to be untrue. Children who are destined to be tall as adults probably have larger heads, and presumably brains, at the same height, than do those who are destined to be short.

It has long been recognized that most malnourished infants and children perform at a level well below that of their "healthy" age peers [4]. Once the acute metabolic derangements are corrected, the level of performance improves, but a significant degree of retardation persists, even in relation to their own siblings [3]. In one report [10] no difference was found in stature or performance when a like comparison was made.

The combination of poor mental performance, behavior problems, and a presumably reduced head size, has led to the assumption that malnutrition in early life causes mental retardation. However, most of the investigators cited believe that it is impossible, in evaluating the mental performance of the children that they have studied, to separate the effects of malnutrition from those of the environment that led to the malnourished state.

\section{Materials and Methods}

During the past 9 years we have recruited over 110 families of severely malnourished infants, and have followed these families closely in their homes in the peripheral slums of Lima, Peru. The appalling environment and the disastrous home circumstances typical of these families have been described [8]. In 13 of them, one or more later born siblings were admitted to our convalescent unit shortly after birth and given an ideal diet in a protected environment until the age of 18-27 months. These 18 infants had all been weaned before 1 month of age, and a mortality of $50 \%$ could be expected by the age of 2 years if they remained at home. Although some of them were already undernouished, they were not sick and responded promptly to an appropriate diet. They are hereafter referred to as "controls." Our plan of study was carefully explained to the parents and written consent was obtained. Frequent visits were fostered and every attempt was made to provide a maximum of stimulation. We felt confident that the advantages of survival and a better start in life would outweigh the disadvantages of an "institutional" setting, particularly when this was compared with the disastrous home environment.

We have followed the growth of these children cluring the first 24-54 months of life and compared this growth with that of their severely malnourished siblings and that of so-called "healthy" siblings who, although undoubtedly undernourished, were never sick enough to be hospitalized.

In the same 13 families there were 15 children originally admitted to our metabolic unit with the diagnosis of severe malnutrition. After 6-12 months of intensive rehabilitation they were returned to their homes. They are hereafter referred to as "malnourished." One of them had been admitted at 28 months of age with kwashiorkor; the rest were less than 15 months of age, with a mean admission age for the group of 10.6 months.

In the same 13 families there were 40 children, some older and some younger than the malnourished, who were never admitted to our unit and are hereafter referrecl to as "healthy," realizing full well that all of these children probably were or had been chronically undernourished.

In analyzing growth, when there was more than one child from one family in any of the three categories, the average was taken, so that a family with particularly tall or short genetic stature would not be unduly weighted in any category. The " $n$ " used in statistical analysis was that of the number of families, ignoring the number of children in each family.

Body weight was not taken into account as it is subject to wide fluctuations over short periods of time. 
Recumbent length (or standing height after 6 years of age) was taken as the measure of growth because this variable predicts fairly accurately the lean body mass, the muscle mass, and the number of muscle cells in normal children [1]. Even when the convalescent malnourished child attains the expected weight for height, or even for age, he generally has a significant deficit in length, as well as in muscle and visceral cell mass [2, 7]. Even in the severely malnourished state, however, body length quite accurately predicts muscle cell number [2].

Throughout most of this report, body length (or height) is expressed as a height "quotient," using the 50 th percentile of the Boston standard [14] as the reference. The age to which a given measurement corresponds on this reference standard, expressed as a percentage of chronologic age, is the "height quotient." The same method was used for "head circumference age" in previous reports from our unit [6]. Occipitofrontal head circumference is a generally accurate predictor of brain weight and of brain cell number, estimated from the total DNA content [16].

Thirteen of the 18 controls, representing 12 families, were returned to their homes at 18 months of age. Five of them, representing five families, remained in the convalescent unit until 24 months of age or longer. In four families there was one control sibling with a "short" stay and one with a "long" stay.

During the stay in the convalescent unit, control children received a diet based on modified cow's milk, with other foods added to the dict at the ages which are customary in the United States. The children were fully immunized and received prompt medical care for any illness. Only when it was absolutely necessary were interruptions permitted in their full cliet.

The very protected nature of the environment in our unit may have contributed to the precipitous loss of height quotient experienced by our control children upon their return home. They were spoon-fed and pampered in other ways, leaving them unprepared to cope with the obligatory neglect which they were to experience at home, where, no matter how well intentioned the mothers, they did not have the time and the conveniences necessary to maintain the level of food intake established in our unit. On the basis of this experience we have more recently insisted that all children be able to feed themselves and be accustomed to the nature of family food items before they are discharged. Recent observations suggest that they are then more likely to hold on to the advantages of a better nutritional start in life.

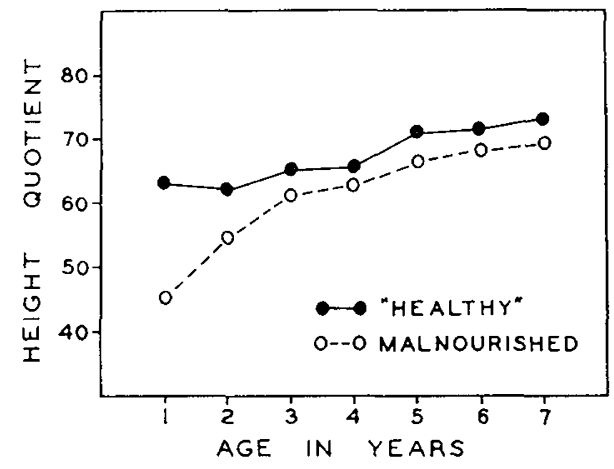

Fig. 1. Evolution, from 1 to 7 years of age, of height quotients (height age $\times 100 /$ chronologic age) for 15 severely malnourished infants and 40 so-called healthy siblings from 13 very poor families.

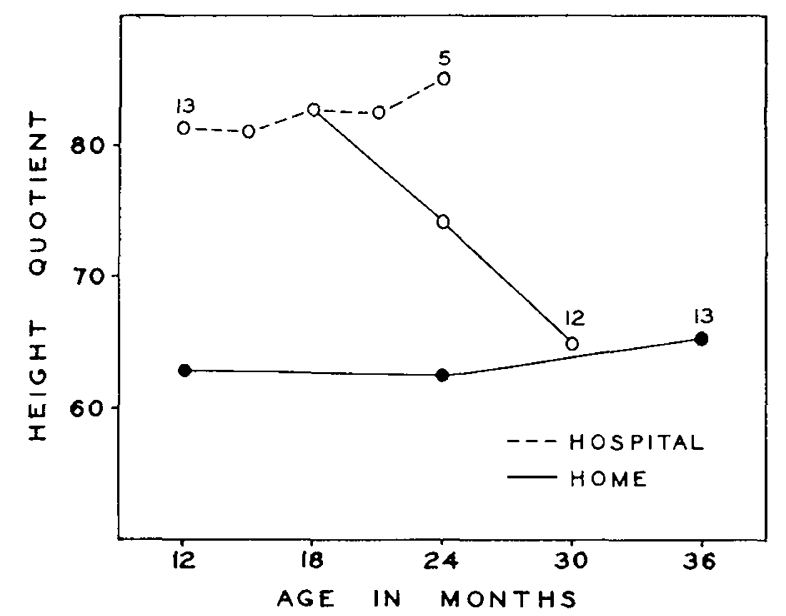

Fig. 2. Height quotients, from 12 to 36 months of age, of $40 \mathrm{so}$ called healthy children in 13 families (closed circles and solid lines), compared with those of 18 siblings (open circles) from the same 13 familics who received optimal diets in a convalescent hospital from shortly after birth until 18-27 months of age. All were in the hospital (broken line) until 18 months of age: 5 children from 5 families remained until 24 months or longer (broken line), while 13 children from 12 families returned home at this time (solid line).

\section{Results}

Figure 1 depicts the evolution of the height quotients from 1 to 7 years of age in the malnourished children and in the healthy siblings. Children growing along the 3rd percentile of the Boston standard have height quotients very similar to those of the healthy children in this study. At 1 and 2 years of age the malnourished children were significantly shorter than their healthy siblings $(P<0.05)$. From 3 to 7 years of age the differences were no longer significant.

Figure 2 compares the height quotients of control 


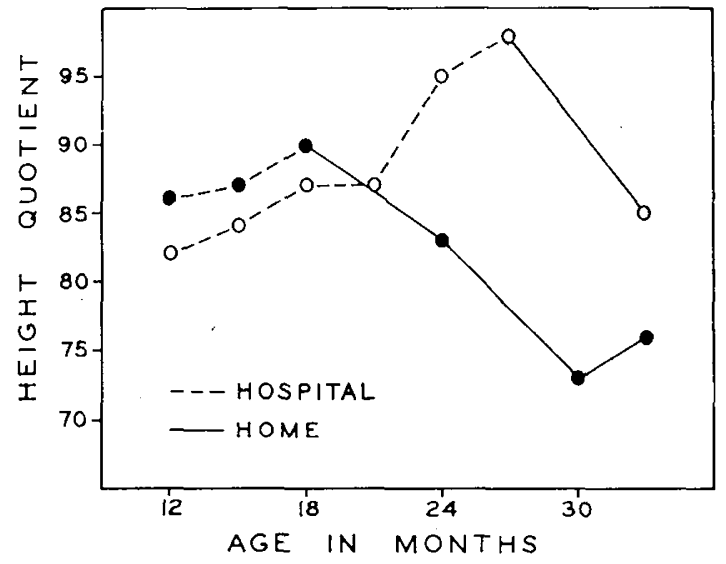

Fig. 3. Hcight quotients, from 12 to 33 months of age, of monozygotic twin girls who were in a convalescent hospital (broken lines) until 18 and 27 months of age, when each returncd home (solid lines).

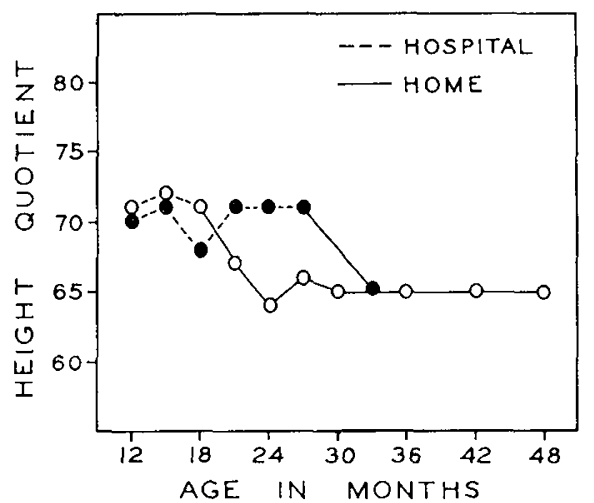

Fig. 4. Height quotients of a boy (open circles) and his sister (closed circles) who were in the convalescent hospital (broken lines) from shortly after birth until 18 and 27 months of age, respectively. Time at home is represented by solid lines.

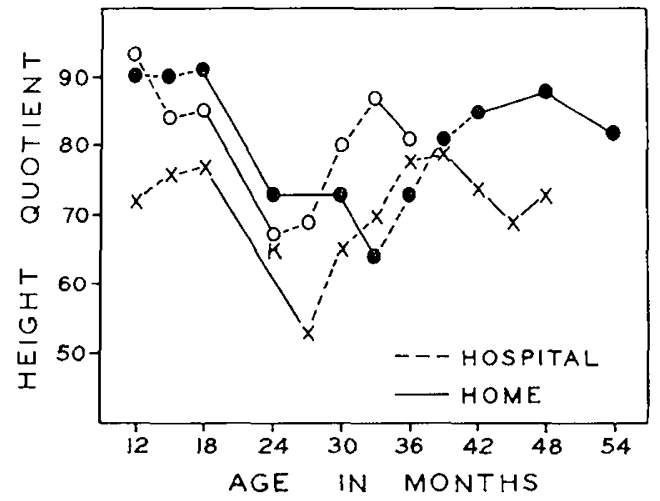

Fig. 5. Height quotients of three unrelated girls who were discharged from the convalescent hospital at 18 months of age and readmitted 6-15 months later, one with kwashiorkor $(K)$. Time in the hospital is indicated by broken line; at home, by solid line. chiidren with those of the healthy siblings. From 12 to 18 months of age all 13 families are represented in the control group. From 18 months of age and older they are separated into the 5 children who remained in the convalescent unit, representing 5 families, and those who returned home, 13 children from 12 families. At 18 months of age, those who returned home actually had a higher mean quotient, 84.7, than those who remained, 81.0. The difference was not significant $(P>$ $0.1)$. The slight increase in height quotient after 18 months of age in those who remained is due to the continued making up of the deficit which existed originally in twins who are depicted separately in Figure 3. At 24 months of age there was already a significant difference $(P<0.05)$ between those who remained and those who returned home. By 30 months of age the height quotients of the controls who returned home 12 months earlier were indistinguishable from those of the so-called healthy siblings. At 12 and 18 months of age there had been a striking difference between the two groups $(P<0.02)$.

Figure 3 illustrates data obtained from monozygotic twin girls; one went home at 18 months, the other at 27 months of age. Whereas one nearly stopped grow ing, the other, as already inclicated, continued to advance toward the 50 th percentile of the Boston stanclard, represented by a height quotient of 100 . When she returned home, her growth also slowed.

Figure 4 represents two control siblings: one, a boy, returned home at 18 months and was followed until 48 months of age; the other, a girl, remained in the unit until 27 months of age. It is apparent that their genetic potential was low, placing them near the 3rd percentile of the Boston standard. At home they dropped further; the boy then continued to grow at a steady rate, maintaining the same height quotient for nearly 2 years. Their malnourished brother, admitted at 28 months with kwashiorkor, now has a slightly higher quotient than either control sibling. Two healthy siblings have similar height quotients.

Figure 5 illustrates data concerning three unrelated control girls who returned home at 18 months of age and were readmitted 6-15 months later, one with kwashiorkor. Their ability to make up lost growth promptly was much greater than that seen in children admitted to the unit with similar deficits acquired over a longer period of time [6].

We estimated the radiologic bone ages [9] of these children at comparable ages. At approximately 4 years of age, the height age of the malnourished was $60 \%$ of chronologic age (Fig. 1), whereas bone age was $64 \%$ of 
chronologic age. At 3.5 years of age the height age of the healthy siblings was $65 \%$ and bone age was $69 \%$ of chronologic age. At a mean age of 3 years the height age of the total control group was $74 \%$ and bone age was $84 \%$ of chronologic age.

Figure 6 relates head circumference of control and malnourished boys to their height (in centimeters), up to 3 and 6 years of age, respectively. The lines which form the upper and lower limits of the shaded area relate the same measurements in boys growing along the U.S. 50th and 3rd percentiles up to 4 and 5 years, respectively: At the same height but at a younger age, boys from the 50th percentile have head circumferences which are about $2.5 \mathrm{~cm}$ greater than those of the 3rd percentile. The differences between the control and malnourished groups were not significant. The control group at 1 year of age and the malnourished group at 3 years of age begin to have greater head circumferences, at the same height, than clocs the U.S. 3rd percentile, suggesting that they belong to a different population. In the control group seven families were represented and the standard deviations of the mean head circumference at each age were all around $1 \mathrm{~cm}$. In the malnourished group eight families were represented and the standard deviations at each age were between 1.5 and $2.1 \mathrm{~cm}$.

In Figure 7 the same measurements are depicted for girls, the controls up to 3 years and the malnourished up to 7 years of age. The two curves are almost indistinguishable and at approximately 2 years of age both groups exceeded the 3 rd percentile in head circumference. In the control group eight families are represented, with a standard deviation of less than $I \mathrm{~cm}$ at each age. In the malnourished group only five families are represented, with standard deviations from the mean head circumference of $0.7-1.9 \mathrm{~cm}$ at each age.

Both the malnourished boys and girls made greater gains in height and head size, the result of catch-up growth, between 2 and 3 years of age, than did the controls, most of whom grew poorly at home during the same time.

\section{Discussion}

One of the outstanding problems in international health is the selection of appropriate standards of reference for the growth of children in underdeveloped areas. It is customary to advise the use of the upper economic decentile as a standard for the rest of the population. In Peru, as in many other countries, this would represent the use of a predominantly Caucasian

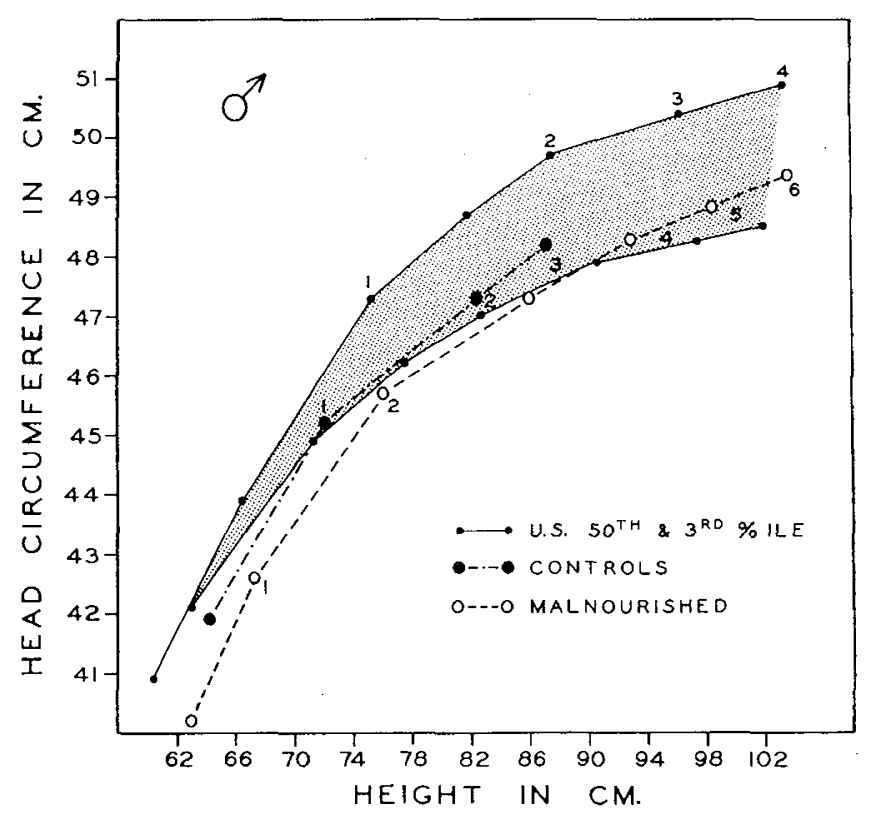

Fig. 6. Head circumference and height, both in centimeters, of boys: upper and lower limits of shaded area represent U.S. 50th and 3rd percentiles, respectively. "Controls" and "malnouxished" are from present study. Numcrals along lines correspond with age in years of the nearby points.

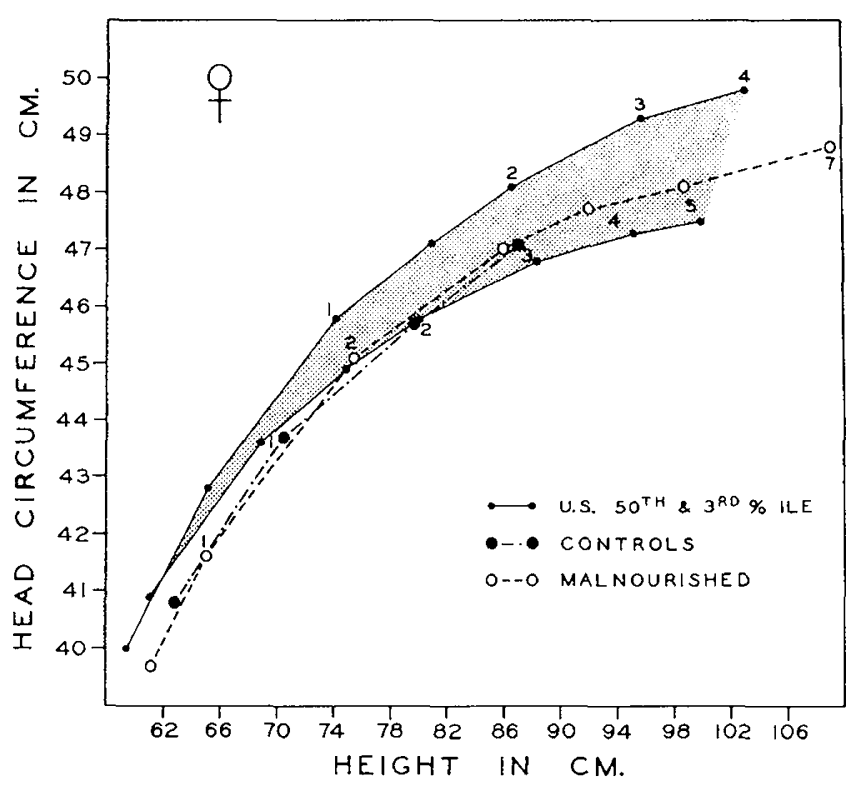

Fig. 7. Head circumference and height of girls: upper and lower limits of shaded area correspond to U.S. 50th and 3rd percentiles. "Controls" and "malnourished" are from present study. Numerals along lines correspond with age in years of the nearby points.

group as a standard for a mixed Andean IndianMestizo population. The alternative of using growth curves derived from a sample of the total population 
would, in a poverty-stricken society, almost certainly underestimate the true genetic growth potential by a wide margin.

The present limited set of observations permits a series of tentative conclusions.

A series of severely malnourished infants and small children, within 2 years of original admission to the hospital, had virtually matched the linear growth of so-called healthy siblings, suggesting that a finite period of severe undernutrition in early life had not resulted in stunting greater than that which is characteristic of all children in the same families. It also indicates that "catch-up" growth can go on for many years, not just a few months [12].

A number of children from the same families were given an optimal diet in a protected environment from shortly after birth until 18-27 months of age: linear growth far outstripped that of malnourished and socalled healthy siblings. Within a year of return to the home environment, growth rate had slowed so dramatically that they were practically indistinguishable in relative stature from siblings. Upon readmission to the protected environment, three of them made up the recently acquired deficits in less than 6 months, suggesting a much greater catch-up potential than that of chilchen who acquire a similar deficit over a longer span of time. This result is quite analogous to the experience observed in experimental animals [15].

Head circumference was no more severely affected by malnutrition in early life than stature, and had just as much catch-up potential in this group of children. It seems to be just as much a function of stature as is lean body mass.

These observations, with regard to stature, are confirmatory of those made by others $[5,10]$. By making available truly healthy controls from the same families, they indicate that nearly all children in very hostile environments grow well below their genetic potential. They further suggest that for a given adverse home situation there is a characteristic growth pattern that over the years tends to mask much of the genetically determined difference between families as well as any early differences resulting from the state of nutrition and health in the first 2 or 3 years of life.

If it is true that brain, because of its more rapid rate of growth in the first 2 years of life, is less able to make up deficits acquired during this time, then we should have found that our control children, after their linear growth rate slowed down at home, had larger heads, at the same height, than did their malnourished siblings. This was not the case in this relatively small group, suggesting that the period of growth in head circumference, and presumably brain mass, can be stretched out, as is the case for linear growth.

From the data presented here we can say nothing about present or future "intelligence" of these children. We can suggest, however, that malnutrition in early life may have no apparent selective effect on head growth. When head circumference, brain weight, or brain DNA content of malnourished children is expressed as a function of chronologic age [17] instead of as a function of height or lean body mass, both good expressions of biologic age, erroneous conclusions may be drawn. Such studies need to be complemented by similar ones of recovered children who have died from other causes. If severe malnutrition in early extrauterine life affects future "intelligence," over and beyond the effects of an adverse environment, our own evidence, and that of others, as to the head size of previously malnourished children does not support such an important deduction.

In a favorable environment, including adequate nutrition, the growth rate of healthy children is almost exclusively a function of their inheritance. In the disastrous circumstances in which most of the world's children live, growth rate is at least equally a function of the environment during the entire growth period, with the plane of nutrition assuming a very important role. This in turn is cletermined by the quantity and quality of food available, by the time and conveniences which the mother can devote to feeding her children, and by the number and duration of infections which interfere with the offering of food, its intake, and its utilization. It may well be that the much slower rates of growth and the smaller statures achieved by children in adverse situations are a convenient adaptation for survival.

\section{Summary}

A group of severely malnourished infants and children from very poor families in Peru, after initial rehabilitation in the hospital, caught up in stature with a group of their so-called healthy siblings. When compared with truly healthy and well nourished siblings, both groups were found to be equally stunted. The advantages of optimal growth during the first 18-27 months of life were apparently wiped out by return to an unfavorable home environment within as little as 12 months.

Children whose nutrition was optimal during the first 2 years of life did not have greater head circumfer- 
ences, at the same height, than siblings who were malnourished during a significant part of the same period, suggesting that there was no selective effect of malnutrition on brain mass, other than a retardation in growth proportional to that in stature and presumably lean body mass.

\section{References and Notes}

1. Cherk, D. B. (Ed.): Human Growth: Body Composition, Cell Growth, Energy, and Intelligence. (Lea \& Febiger, Philadelphia, 1968).

2. Chirk, D. B., Hill, D. E., Cordano, A., and Grajam, G. G.: Malnutrition in infancy: changes in muscle and adipose tissue before and after rehabilitation. Pediat. Res., 4: 135 (1970).

3. Cravioto, J., and Delicardie, E. R.: Mental performance in school age children. Findings after recovery from early severe malnutrition. Amer. J. Dis. Child., 120: 404 (1970).

4. Cravioto, J., AND Robles, B.: Evolution of adaptive and motor behavior during rehabilitation from kwashiorkor. Amcr. J. Orthopsychiat., 35: 449 (1965).

5. Garrow, J., And Prke, M. C.: The long-term prognosis of scvere infantile malnutrition. Lancet, $i$ : 1 (1967).

6. Gratiam, G. G.: The later growth of malnourished infants; effects of age, severity, and subsequent diet. In: R. A. McCance and E. M. Widdowson: Calorie Deficiencies and Protein Deficiencies, p. 301 (Churchill, London, 1968).

7. Graham, G. G., Cordano, A., Blizzaki, R. M., and Cheek, D. B.: Infantile malnutrition: changes in body composition during rehabilitation. Pediat. Res., 3: 579 (1969).

8. Graham, G. G., and Morales, E.: Studies in infantile malnutrition. I. Nature of the problem in Peru. J. Nutr., 79: $479(1963)$.

9. Grruirch, W. W., ANd Pyle, S. I.: Radiographic Atlas of
Skeletal Development of the Hand and Wrist. (Stanford University Press, Stanford, Calif., 1959).

10. Hansen, J. D. L., Freesemana, C., Moodre, A. D., and Evans, D. E.: What does nutritional growth retardation imply? Pediatrics, 47: 299 (1971).

11. Nerimaus, G.: Head circumference from birth to eighteen years. Pediatrics, 4I: 106 (1968).

12. Prader, A., Tanner, J. M., and Von Harnack, G. A.: Catchup growth following illness or starvation. An example of developmental canalization in man. J. Pediat., 62: 646 (1963).

13. STOCI, M. B., AND SMYTur, P. M.: The effect of undernutrition on subscquent brain growth and intellectual development. S. Afr. Med. J., 41: 1027 (1967).

14. STUan', H. C.: In: F. H. Harvic: Pecliatric Methods and Standards, p. 21. (Lea \& Febiger, Philadelphia, 1958).

15. Wrdoowson, E. M., ANd MCCance, R. A.: 'The effect of finite periods of undernutrition at different ages on the composition and subsequent development of the rat. Proc. Roy. Soc. Ser. B Biol. Sci., 158: 329 (1963).

16. WINICK, M.: Changes in nucleic acid and protein content of the human brain during growth. Pediat. Res., 2: 352 (1968).

17. W INICK, M., AND Rosso, P.: Head circumferences and cellular growth of the brain in normal and marasmic children. J. Pediat., 74: 774 (1969).

18. The authors are indebted to Dr. Carlos A. Muhletaler of the Department of Radiology, The Johns Hopkins Hospital, for the bone age estimations.

19. Presented in part at the 40th Annual Meeting of the Society for Pediatric Research, Atlantic City, N. J., May I, 1970.

20. Supported by Public Health Service Rescarch Grant no. AM09980 from the National Institute of Arthritis and Metabolic Discases, National Institutes of Health.

21. Requests for reprints should be addressed to: George: (;. Graham, M.D., 615 North Wolfe Strect, Baltimore, Md. 21205 (USA).

22. Accepted for publication January 29, 1971. 